\title{
Assessment of the Teaching of Pattern Making and Freehand Cutting Skills in Ghanaian Senior Secondary Schools
}

\author{
Modesta Efua Gavor, Patience Asieduah Danquah \\ Department of Vocational and Technical Education, University of Cape Coast, Cape Coast, Ghana \\ Email address: \\ nuworzamodesta@yahoo.com (M. E. Gavor), prayfat1@yahoo.com (P. A. Danquah)
}

\section{To cite this article:}

Modesta Efua Gavor, Patience Asieduah Danquah. Assessment of the Teaching of Pattern Making and Freehand Cutting Skills in Ghanaian Senior Secondary Schools. International Journal of Vocational Education and Training Research. Vol. 4, No. 1, 2018, pp. 8-12.

doi: 10.11648/j.ijvetr.20180401.12

Received: February 11, 2018; Accepted: March 19, 2018; Published: April 10, 2018

\begin{abstract}
The purpose of the study was to investigate the extent to which the content of freehand cutting and patternmaking are covered in the Senior High Schools (SHSs). All clothing students enrolled in the clothing and textiles option of the Home Economics programme at the University of Cape Coast for the 2015/2016 academic year were used for the study. A questionnaire was used to collect the needed information. The data for the study were analysed with the help of descriptive statistics. Results of the study indicate that although what freehand cutting means together with its advantages and disadvantages are being taught in Ghanaian SHSs, very few students are exposed to the practical skill of freehand cutting. The results also show that although attention is paid to drafting of basic blocks very little attention is given to adaptations for various designs. At the West African Certificate examinations level although questions are set on the skill of patternmaking no questions are set on the practical aspect of freehand cutting. It is suggested that much attention is given to the teaching of freehand cutting at SHS. In addition, more books on freehand cutting should be written to encourage its teaching at the SHS levels in Ghana.
\end{abstract}

Keywords: Pattern Making, Freehand Cutting, Teaching, Secondary School

\section{Introduction}

A major objective of the Ghanaian educational system, is to equip individuals with employable skills to enable them contribute meaningfully towards the development of the nation (Charway, 2002). Based on this, Technical Vocational Education and Training (TVET) subjects were introduced into the secondary school curriculum in the mid-1960s, and in 1987 a comprehensive plan was initiated to make 'vocational education' an integral part of the secondary education system (Charway, 2002). Among the TVET subjects offered at the secondary level is Clothing and textiles which is part of Home Economics. Consequently, the main aim of teaching Clothing and Textiles is to train students to acquire knowledge and skills in clothing production and management. The scope of content of the Clothing and Textiles programme for Senior High Schools (SHS) has therefore been designed in such a way as to offer skills that are terminal and can be put to immediate use apart from providing the foundation for further studies in areas of Clothing and Textiles (Ministry of Education, 2010). The students are expected to learn various ways of constructing garments including pattern making. According to Bhati (2018), the development of a garment comprises different processes such as pattern making which is the art of manipulating and shaping a flat piece of fabric to conform to the human figure. Apart from the use of commercially made patterns for garment construction, the free hand cutting method is also used in the construction of garments.

Patternmaking has however been shown to be the main method of cutting out fabric taught in the university (Foster \& Ampong, 2012). One may be tempted to conclude that with this background of the graduates who become the ultimate teachers at the secondary school, they will concentrate on teaching what they know best in cutting out.

In the universities especially, experience has shown that 
lecturers get frustrated when they start teaching the first course in flat pattern designing to students. Students seem blank on basic concepts which are assumed that they should have known from the SHS. There have been speculations on the inadequate teaching of freehand cutting and patternmaking at the SHS level. There is very little empirical evidence to support this assertion. The purpose of this paper was to assess the extent to which the adequate teaching of patternmaking and freehand cutting are being achieved in SHSs in Ghana. It was anticipated that the outcome of the study would help establish the extent to which patternmaking and freehand cutting are taught at the SHS level in Ghana.

The objectives of the study were to:

1. analyse the extent to which the content of patternmaking and freehand cutting are covered at the SHS level.

2. evaluate any differences in the teaching of patternmaking as against freehand cutting.

\section{Literature Review}

According to Charway (2002), as an integral part of its plan for economic recovery through the education of the youth for work, the government of Ghana initiated the 1987 Education Reform Programme (ERP) to reverse the decline in the education system. It was agreed that providing vocational education at the secondary school level would equip students with skills for paid and self-employment. Consequently, technical vocational training became an integral part of the secondary education system in Ghana. As indicated earlier at the introduction section, clothing and textiles which is part of the home economics programme is among the TVET programmes introduced at the secondary school level.

Forster and Ampong (2012) indicated that the clothing and textiles training programmes in Ghanaian schools are expected to develop students' competencies in designing, pattern making and garment cutting, assembling and finishing of garments. Therefore, students who are not able to gain knowledge and skills in any of the aspects indicated are likely to find it difficult to gain employment in the garment industry or become self-employed which is the main aim for the introduction of the programme. The pattern making methods taught in Ghanaian Schools include Draping, Drafting and cutting directly on the fabric termed freehand cutting (Forster \& Ampong, 2012). In the free hand cutting method, the design is cut straight from the fabric without using any elaborate patterns (Foster \& Adamptey, 2009).

The SHS syllabus for clothing and textiles produced by the Ministry of Education (2010) indicates that during the teaching and learning of freehand cutting, teachers are to demonstrate how to cut a sleeveless top to students and then supervise students to cut a similar top with the method, first using paper and do same on fabric. To make sure students practice freehand cutting, the syllabus suggests that each student should complete the garment he/she cuts for evaluation. The theory content relating to freehand in the
SHS syllabus (2010) deals with what freehand cutting is, its advantages and disadvantages.

In terms of patternmaking, the SHS syllabus expects students to be taught for theory the importance of patternmaking, types of patterns, types of commercial patterns, methods of making patterns and pattern symbols. For practical skills in patternmaking, students are to gain knowledge in drafting the following basic blocks - bodice, skirt, torso and shirt. They are also to adapt the basic blocks for the following details - princess line, horizontal yokes, dress blocks, simple shirt collar and A-line skirt.

However, research has shown that freehand cutting is the most common method of cutting out used by the small scale industry in Ghana (Fianu \& Zentey, 2000), but very little of it is taught at the tertiary level (Foster \& Ampong, 2012). Meanwhile, it is at the tertiary level that teachers are trained to teach all levels of education in Ghana (Foster \& Ampong, 2012). One would then wonder how these trained teachers would be able to impact knowledge on freehand cutting to their students and if patternmaking which is known to be well taught at the tertiary levels is well impacted to students at the SHS levels in Ghana. Therefore, this paper aimed at assessing the current state of the teaching of patternmaking and freehand cutting for garment construction at the SHS levels in Ghana.

\section{Methodology}

In order to assess the teaching of pattern making methods at the SHS levels in Ghana, a descriptive survey was employed and the data were collected at a single point in time. The content of the SHS syllabus published in 2010 was also examined. Students from levels 100 to 400 offering clothing and textiles at the University of Cape Coast during the $2015 / 16$ academic year were employed for the study. The total number of clothing and textile students for the 2015/16 academic yearwas 75 . The respondents were selected purposively to include all those in the programme who entered the university from SHS and offered clothing and textiles at that level. Those who were in the same programme but did not offer clothing and textiles at the SHS level were excluded. The total number of respondents was therefore 55 . A questionnaire was developed for the data collection and most of the questions were closed ended and based on the 2010 SHS Ghana Education Service (GES) syllabus for clothing and textiles. The questionnaire sought to find out the background of the students; the content and practical skills they were taught in terms of freehand cutting and pattern making.

Data was collected by giving questionnaires out to students during second half of the second semester of the 2015/16 academic year. The administration was specifically carried out while they were waiting for a practical lesson. The questionnaires were immediately filled and collected. Data collected was sorted out according to the objectives of the research and analysed using mainly descriptive statistics. 


\section{Results}

The background of the respondents indicated that the SHSs they attended covered seven (7) of the ten regions of Ghana with the highest number20 (36.4\%) coming from the central region. The only regions that were not represented were the three northern regions namely northern, upper east and upper west regions. Apart from practical work in school, most students stated they do some sewing on their own with most of them $32(62.7 \%)$ out of the 51 who responded noting they sometimes sew, on a scale of frequently, sometimes rarely and rarely. Only one out of the 51 students said she did not sew at all. On their carrier ambition 20 wanted to be fashion designers followed by 15 who wanted to be lecturers and teachers.

Table 1 provides responses on the content of freehand cutting taught to respondents.

Table 1. Content of freehand cutting taught to respondents.

\begin{tabular}{llll}
\hline Content at the SHS level & Yes & Total & No \\
\hline What freehand cutting is & 50 & 5 \\
Advantages of freehand cutting & 49 & 6 \\
Disadvantages of freehand cutting & 47 & 55 \\
Did your teacher ever do any practical demonstration on freehand cutting? & 41 & 8 \\
Did you make any garment in SHS using free hand cutting? & 42 & 14 \\
Did you cut the garment yourself? & 24 & 55 \\
\hline
\end{tabular}

On the syllabus content taught in their SHSs for freehand cutting, Table 1 shows a high number indicated they were taught the theory that was in the syllabus namely what freehand cutting is, advantages and disadvantages of freehand cutting. Of the 42 students who made garments using freehand cutting only 24 did the cutting themselves. Seventeen of the 42 had the cutting out done by the teacher while one (1) student noted they had a resource person brought in to cut for them.

Table 2 provides the results for the theory content of pattern making taught to respondents.

Table 2. Theory content of pattern making taught to respondents.

\begin{tabular}{llll}
\hline Content & Yes & No & Total \\
\hline The importance of patterns & 44 & 11 & 55 \\
Types of patterns & 41 & 14 & 55 \\
Types of Commercial patterns & 38 & 17 & 55 \\
Methods of making patterns & 36 & 19 & 55 \\
Pattern symbols & 43 & 12 & 55 \\
\hline
\end{tabular}

On the average $73 \%$ of the students were taught the theory aspect of pattern making. When it came to the details however, the most taught areas were importance of patterns and types of patterns, while methods of making patterns was the least taught (Table 2).

Clothing and textiles requires practical skills to make it complete so the researchers wanted to find out the amount of pattern making practical skills taught to the students at the SHS level. Table 3 provides the summary of the responses. The results reveal that although students are supposed to draft various blocks and adapt them for various styles as indicated by the syllabus, the numbers are not encouraging. The block most drafted by respondents was the bodice block (31 out of 55 respondents) with the torso block being the least drafted (13 out of 55). With regard to pattern adaptation, Table 3 shows that respondents mostly adapted simple dress blocks and simple shirt collar with horizontal yokes being the least adapted design.
Table 3. Practical pattern making skills taught to respondents.

\begin{tabular}{llll}
\hline Drafted basic blocks & Yes & No & Total \\
\hline Bodice & 31 & 24 & 55 \\
Skirt & 22 & 23 & 55 \\
Torso & 13 & 42 & 55 \\
Shirt & 16 & 39 & 55 \\
Adapted designs & & & \\
Princess lines & 15 & 40 & 55 \\
Horizontal Yokes & 14 & 40 & 54 \\
Dress blocks & 24 & 31 & 55 \\
Simple shirt collar & 24 & 31 & 55 \\
A-line skirt & 22 & 33 & 55 \\
\hline
\end{tabular}

Table 4. Content of pattern and freehand cutting covered in the final exams.

\begin{tabular}{llll}
\hline Presence of content in exams & Yes & No & Total \\
\hline $\begin{array}{l}\text { Did your WASSE exams have any practical } \\
\text { oriented questions on freehand cutting? }\end{array}$ & 10 & 39 & 49 \\
$\begin{array}{l}\text { Did your WASSE exams have any practical } \\
\text { oriented questions on using paper patterns? }\end{array}$ & 44 & 9 & 53 \\
\hline
\end{tabular}

The researchers wanted to find out the extent to which the content to be taught was in the SHS texts used by students and if questions on the contents in question were asked in the final exams. A look into the recommended texts indicated that the text books being used by students had more content in terms of theory than practical skills especially in the area of freehand cutting. Crosschecking also confirmed that until 2014 no recommended texts for SHS dealt with the practical skill of cutting freehand. However in pattern making both theory and skills areas were covered.

As shown in Table 4, practical questions in freehand cutting are not usually asked in the final certification of the students with only ten out of 49 students noting they had questions on freehand cutting in their exams as against 44 out of 53 respondents noting there were questions on pattern making in general.

\section{Discussion}

According to the West African Senior School Certificate 
Examination (WASSCE) syllabus in Clothing and Textiles, the three profile dimensions that have been specified for teaching, learning and testing are: Knowledge and Understanding 15\%, Application of Knowledge 25\% and Practical Skills $60 \%$. The results of this study however shows that practical skills acquisition in the areas of making pattern and free hand cutting are not getting their fair share of the $60 \%$ demanded by the syllabus. Free hand cutting as a skill is mainly demonstrated by teachers with just about half of the students being allowed to do their own cutting. In the making of garments using freehand cutting it seems the focus is more on the construction processes instead of the skill of cutting out which is the focus of that content. Consequently, students' skills in pattern making would be affected. As indicated by the Central Board of Secondary Education of India (2014), the accuracy of any pattern making method depends largely on relevant and correct measurements, therefore "learning pattern making by trial and error is like learning to play music by ear." It is only when teachers have the skills in freehand cutting that they can have the confidence to teach their students. Research by Foster and Ampong (2012) indicates that in two Universities where clothing and textile teachers are trained in Ghana, the concentration is more on pattern making than freehand cutting. This means they will not be very comfortable teaching the skill of freehand cutting. The fact that there is very little on the skills of freehand cutting in the text books available at the SHS level aggravates the situation. Teachers and students have no source of reference material making it difficult to have a standard of freehand cutting to use. It is no wonder that there are no questions in the final exams from West African Examinations Council (WAEC) on freehand cutting. The difficulty here is what the standard for the marking will be since every teacher uses his or her own method to teach the students. It is also these same teachers who will be marking the scripts and if they are not good at the skill it will be disastrous to leave the marking to their discretion. With very little being asked on the skill of freehand cutting in the final exams the temptation is for some teachers not to teach the skill at all since it will not affect their performance in the final exams.

In pattern making, the story is not very different. About a quarter of students are not taught drafting or adaptation. Teachers decide on which of the topics to teach and leave out the rest. For both drafting and adaptation there was not a single topic in which all the students noted they were taught. With the directions in their texts, however students may read by themselves and ask for clarification.

The scope of the content of the Clothing and Textiles programme for Senior High School (SHS) was designed to offer skills that are terminal and can be put to immediate use apart from providing a foundation for further studies. One of the crucial skills in the clothing industry is the cutting out of articles (Jauch \& Traub-Mere, 2006). Students for whom the SHS is terminal, it is imperative that they get a very good foundation in cutting out if they should decide to practice the skill of clothing construction. Research has shown that freehand cutting is the main method of cutting out used by the local clothing construction industry in custom sewing (Fianu \& Zentey, 2000). Custom sewing being the most prevalent method of making garments in Ghana makes it imperative for anyone taking clothing and textiles as a course in the secondary school to have basic knowledge in freehand cutting. Research again points to the fact that although freehand cutting is easier and the main method of cutting out in the Ghanaian sewing industry (Forster, 2007), the practitioners acknowledge the fact that pattern making becomes very important where the style is complicated and where a high level of close fit is desired. Aldrich (2011) notes that flat pattern designing is widely used because of its accuracy and speed with which model sizes can be graded to get different sizes. It is therefore, imperative for both forms of cutting out to be given attention in the secondary school. One acknowledges that the skills cannot be perfected at that level, however when provided with a good foundation it can be gradually built upon by the graduates.

\section{Conclusion}

The aim of clothing and textiles syllabus to have students gaining knowledge in cutting out clothing articles is not being fully realised with only about $52 \%$ of the students having attempted cutting out a garment using free hand cutting and about $70 \%$ of the students being taught the basics of pattern making. The texts used at the SHS have adequate information on pattern making skills but that for freehand cutting is virtually absent thus making it difficult for both teachers and students to have any references for freehand cutting. With no books on freehand cutting there is no standard to use in setting the final exams taken by all SHSs thus making freehand cutting skill absent in the final exams Set by the WAEC.

\section{Recommendations}

It is evident from the study that there are virtually no references on freehand cutting in terms of text. Being part of the syllabus and the most common method of cutting out used by clothing producers in Ghana, it will be in place for the Ghana Education Service to put measures in place that will come out with texts on freehand cutting for use by schools. Making the basic blocks alone are of no use if the students cannot adapt them into various styles. Teachers in the SHSs should therefore make it a point to at least have students draft the entire basic blocks and do the adaptations that are required for each of the basic blocks. Instead of students making samples of all constructional processes, they should be incorporated into useful articles. Freehand cutting could be introduced very early in the SHS programme, probably during the third term of the first year. This way the student can cut out useful articles which they can make using skills acquired in the constructional process.

Although the sample used was made up of students who attended SHS in almost all the regions in Ghana it would be 
good to replicate the study using a sample who are currently in SHS. Also teachers were excluded from the study thus providing information on the students' perspective only. Including teachers in a follow up study may help provide reasons why the skills are not being taught as they should and thus providing a starting point for stake holders in education for solving the problem.

\section{References}

[1] Aldrich, W. (2011). Metric Pattern cutting for Men's Wear $\left(5^{\text {th }}\right.$ ed.). Oxford: Wiley-Blackwell.

[2] Bhati, M. (2018). Basics of pattern making. Retrieved February 29, 2018, from www.fibre2fashion.com.

[3] Central Board of Secondary Education India (2014). Basic pattern development: students handbook+practical manual class XII.

[4] Charway A. S (2002). "Encouraging vocational education in Ghana (III)". Daily Graphic. January, 29, p. 7, col. 2-4.
[5] Fianu D. G, Zentey EA (2000). Problems of large-scale fashion designers in Accra, Ghana. J. Consumer Stud. Home Econs., 24 (2), 128-136.

[6] Forster P, Adamtey S (2009). A manual for freehand cutting of garments. Accra: Asante and Hittscher Printing press.

[7] Forster P. (2007). Dressmaking education as a factor for employment in the dressmaking industry in Ghana. J. Educ. Teach., 1 (4), 1-7.

[8] Forster, P., \& Ampong, I. (2012). Pattern cutting skills in small scale garment industries and teacher education universities in Ghana. International Journal of Vocational and Technical Education, 4 (2), 14-24.

[9] Jauch H., Traub-Merc R. (2006). The future of the Textiles and Clothing industry in Sub-Saharan Africa. Conference resolution. Germany: Fredrich Ebert Sterling.

[10] Ministry of Education, Republic of Ghana (2010). Teaching syllabus for clothing and textiles (senior high school 1 3).Accra, Ghana: Curriculum Research and Development Division (CRDD). 